\title{
Multilingualism, language policy and creative writing in Kenya
}

\author{
Esther K Mbithi
}

\section{Correspondence:}

mbithimart@hotmail.com

Kenyatta University, Nairobi, Kenya

\begin{abstract}
Language use and creative writing go hand in hand. In the process of exploring language, we also engage in the study of literature. An engagement with literature is, indeed, a continuing process of improving our capacity to use language and refining our sensibility to good language use. In Kenya, there are clearly discernible patterns of creative writing which may be linked to language policies. In this article we trace language policies in Kenya's formal education sector since 1963, drawing parallels between the prevailing policies and the patterns of creative writing. In the first instance it is an overview of literary output in Kenya since 1963. In the process, however, we shall engage in literary appreciation of selected pieces. Our discussion includes creative writing produced locally in English by writers for whom English would not be considered their mother tongue, as well as creative writing in the local languages. The issue of multilingualism and translation is central to our literary appreciation; whether translation is a subconscious activity during the writing process, or is formally undertaken by a different person after the work has been published, or is in the minds of those reading the work.
\end{abstract}

\section{Introduction}

The word literature can be used to denote:

i. All that is written (including instruction manuals), or

ii. All artistic creations made up of words (including oral presentations).

For this article, we shall restrict ourselves to the point of intersection: works of art that are in writing.

In appreciating selected local literary pieces, we celebrate Kenya's linguistic and cultural diversity. It has been postulated that the writing and study of literature not only sharpens our linguistic capabilities, but also makes us more tolerant, more resilient, more flexible, and more analytic. This article anticipates that the new constitutional dispensation in Kenya will require a comprehensive and inclusive language policy. In particular, it is hoped that the various county governments will take up the challenge of investing in Kenya's local languages. 


\section{Creative writing before independence}

In the political entity we know as Kenya today, there are more than forty culturally diverse groups of people, each with its own language. Kiswahili is the national language. Both English and Kiswahili are official languages, but English is the medium of instruction in Kenyan educational institutions. The natural consequence of this is that any Kenyan who has been exposed to the formal education system has also been exposed to English. It follows, therefore, that creative writers who write in English have (potentially) the whole of Kenya for an audience. Not surprisingly, most literary output in Kenya is in English (see Table 1).

Interestingly, some creative works were published in Kiswahili before 1963 (see Table 1: this Table includes all the fictional works on record for the years indicated). The most probable reason for this would be that not many Kenyans had prolonged contact with the formal education system. Creative writers, therefore, expressed themselves in the language that would be understood by the majority: Kiswahili. Furthermore, as Mbaabu (1987) has pointed out, Kiswahili had been encouraged by the colonial administration alongside English prior to 1953. In 1953, it was banned in favour of the mother tongue languages.

Text s produced in Kiswahili in the 1950s continue to be widely read. Some are even integrated into the school curriculum as class readers or prescribed fasihi (literature) texts. The play Nakupenda Lakini (I love you, but...) is one such text. Nakupenda Lakini is a little book with the simple story line of a detective story. The plot is similar to the real life story of one of Kenya's most wanted criminals, Rasta. When Rasta was gunned down in Ongata Rongai, Kajiado district, Kenya, members of his family claimed he was innocent. To this day, Rasta's widow maintains that she is unable to reconcile the character of the man she lived with with that of the "most wanted" criminal the police gunned down.

In addition to Kiswahili, there were texts in the indigenous languages. The fact that these texts continued to circulate after 1963 is an indication of their instructive value. One such text is Nthũ va yek'wa tivo ivvalũkaa (Phlegm does not land where it has been thrown). The literal translation may be misleading, but the little book has a profound moral lesson: jealousy hurts only the person who is jealous. The plot in Nthru va yek'wa tivo ivvalũkaa is similar to that of Cinderella, revolving around the misfortunes of a girl orphan who eventually succeeds and attains happiness in spite of the odds. This is a plot that recurs in numerous stories recorded in oral literature texts.

\section{Misguided language policy at independence}

Such books seem to have become scarce after independence. Kenya attained political independence from Britain in 1963. The months preceding this historic event were

Table 1 Literary output in Kenya - 1963-2009

\begin{tabular}{lcccc}
\hline & Total number & In English & In Kiswahili & \multicolumn{2}{c}{ In other languages } \\
\hline $\mathbf{1 9 5 0 - 1 9 5 9}$ & 4 & 0 & 4 & 0 \\
$\mathbf{1 9 6 0 - 1 9 6 9}$ & 7 & 7 & 0 & 0 \\
$\mathbf{1 9 7 0 - 1 9 7 9}$ & 51 & 34 & 4 & 1 \\
$\mathbf{1 9 8 0 - 1 9 8 9}$ & 94 & 60 & 18 & 8 \\
$\mathbf{1 9 9 0 - 1 9 9 9}$ & 127 & 82 & 40 & 5 \\
$\mathbf{2 0 0 0 - 2 0 0 9}$ & 81 & 63 & 16 & 2 \\
\hline
\end{tabular}


spent in frantic preparation. Political parties were set up. Party manifestos were produced. Policies were formulated for just about every aspect of daily life ... all but for the most basic instrument of communication, language (as cited in Ochieng, 1989, pp. 202-218). The language policy did not change with change in government. Party manifestos before and after independence were not concerned with language. In Kenya, as in other newly independent African states, "the usual practice [was] to honour the foreign European languages with the exclusive status of official languages" (OAU, 1985, p. 18). The Inter Africa Bureau of Languages (BIL) was set up in 1963 under the auspices of the Organisation of African Unity (OAU), to counter this anomaly. Unfortunately, the good intentions of the BIL depended on the political will of the individual member states. For reasons best known to them, the political elite sidelined the indigenous languages in spite of the BIL's openly stated goals:

...To give support and encouragement to the languages of the majority populations as the most effective vehicles of communication to be used in effectively mobilising Africa's majority populations to solve Africa's economic and development ills (OAU, 1985, p. 2).

The end result was the "abnormality" (OAU, 1985, p. 18) of having national languages which enjoyed no privileges, and giving to foreign languages all the rights and privileges of official languages. In Kenya, the preferential treatment of English produced, in turn, an elite government which shunned the indigenous languages. In the end, the indigenous languages suffered what Ricard (2004, p. viii) refers to as "low intellectual estimation".

\section{The language debate}

Fortunately for Kenya, this was also the time that Kenyans exposed to the modern formal education system became power brokers locally in all spheres of life. Some of them realised the danger posed to the local languages by the prevailing [lack of] a language policy. They raised the alarm and created awareness. Consequently, in the late 1970s, there was a sustained campaign from many quarters for newly independent African states to recognise formally and give logistical support to the indigenous languages. There followed heated debates in intellectual circles and acrimonious remonstrations in government offices. In Kenya, Ngugi wa Thiong'o was probably the most vocal proponent of indigenous languages.

Ngugi's language position had been congealing for some time. For ten years after writing A Grain of Wheat (1984), he did not publish. About this silence, Sander and Munro quote Ngugi (1984, p. 48) as saying:

The crisis arose out of the writing of $A$ Grain of Wheat. I felt that the people who fed the novel, that is the peasantry..., will not be in a position to read it. And this is very painful. So I really didn't see the point in writing anything at all.

It is not surprising that by the time he finished writing Petals of Blood, Ngugi finally announced he would no longer produce creative works in English. He resolved his "language issues" by choosing to write in Kikuyu. In the same year, 1977, he produced, with Ngugi wa Mirii, a play Ngaahika Ndeenda (I will marry when I want). At the time there was only one official language in Kenya, English. Ngugi's action was 
considered seditious by the political establishment. For daring to produce a creative work in Kikuyu, Ngugi was detained "on suspicion of being a communist". He lost his university teaching job and eventually he went into exile. Today, with the benefit of hindsight, the whole world sees very clearly that Ngugi's tribulations with the establishment had more to do with the uncensored political message in the work, than with the language in which the work was produced.

\section{The tragedy of censorship}

But the political establishment used him as a sacrificial lamb, and the cost to Kenya, in terms of creative output, is incalculable (see the low level of creative output before 1980 in Figure 1).

Ngugi's "angst" (Soyinka, 1988, p. 35) when using English for creative writing may be a natural consequence of the humiliating circumstances in which he acquired English language skills (Ngugi, 1981, p. 11). For this reason, he is unwilling or unable to do what Chinua Achebe, for example, does in his works:

Chinua Achebe renders the supposed Igbo discourse in English: He excels in reproducing their turns of phrase, their use of proverbs and their set formulas, and representing the world of the village in a way that is equally as acceptable to Nigerian and non-Nigerian readers (Ricard, 2004, p. 194).

This ability on Achebe's part to "choose the right words", this "keen sense of what is in character and what is not", this "instinct for appropriate metaphor and symbol", (Lindfors, 1973, p. 92) is not peculiar to Chinua Achebe. Indeed, as far back as 1929 Mikhail Bakhtin (as quoted in Lodge, 1990, p. 75) made the following observation:

The possibility of employing on the plane of a single work discourses of various types, with all their expressive capacities intact, without reducing them to a single common denominator - this is one of the most fundamental characteristics of prose.

Indeed, elsewhere in his writing, Ngugi displays the same "mastery of the English language" (Lindfors, 1973, p. 92) as do Achebe and others. Ngugi's reaction to the realities of the post-independence era in Africa, however, differed remarkably from that of

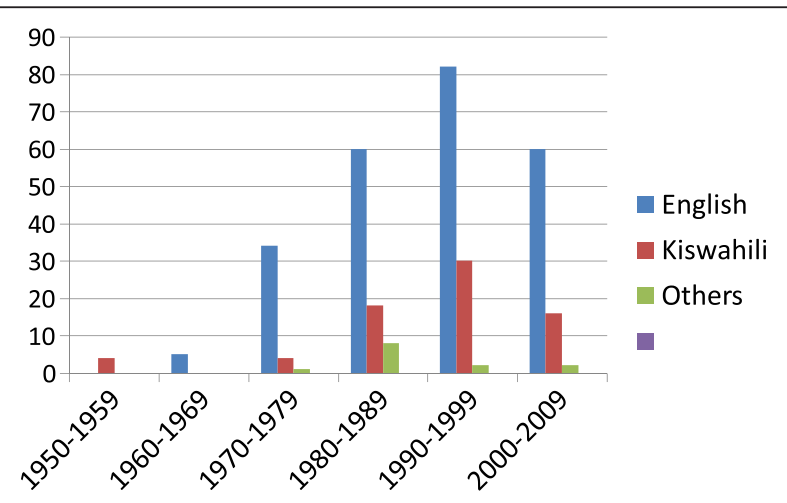

Figure 1 Visual summary of creative writing in Kenya. 
others. When other writers were producing satirical masterpieces, such as Achebe's Man of the People and Ferdinand Oyono's The Old Man and the Medal, Ngugi was labouring over Petals of Blood. Williams (1991, p. 58) rightly observes that Ngugi's language theories cannot be separated from his politics. Predictably, his aesthetics in the 1970s brought him up against the political establishment in Kenya.

\section{The education commissions and language policy}

Kenya came under British rule in 1895. English became the lingua franca in 1929. Kiswahili, which had previously been widely spoken in the East African region, was encouraged by the colonial administration alongside English until 1953 when it was banned. The 1950s were difficult years in Kenya, with emergency rule being declared in 1952. The tensions and undercurrents of those years are expertly captured in Jonathan Kariara's short story 'The Coming of Power' (Kariara 1994).

At least five education commissions have been set up in Kenya between 1963 and 2000. All five have been thoroughly scrutinised by Mbaabu in his 1987 UNESCO/KU manuscript. It is instructive that although these commissions were established to deal with education issues, they all consistently touched on the language question in their recommendations. The first, the Ominde Commission, was set up in 1963 immediately after independence. It published its report in 1964. Although the Ominde Commission ratified the use of English as the medium of instruction, it made a case for Kiswahili so strong that Kiswahili was (re) introduced into the primary school syllabus as a compulsory subject, and a department of linguistics and African languages was set up in Kenyatta University College in 1969.

W. N. Wamalwa and his team published their report in 1972. On their recommendation, two new foreign languages, French and German, were added to the secondary school syllabus. More importantly, they managed to push for Kiswahili to be taught to adults, primarily civil servants, at the Kenya Institute of Administration (KIA) and at the Kenya Institute of Education (KIE). Four years later, in 1976, Gachathi's team expanded the language arena by recommending that Kiswahili be examinable at primary school and that the vernacular languages be used as medium of instruction during the first three years of primary school.

It was Gachathi's team that highlighted the crucial issue of instructional materials. For the foreign languages, English, French and German, there were foreign governments who were quietly expending resources in the teaching of their languages. It was noted that even though Kiswahili had become a compulsory subject in primary school in 1964, very little had been achieved in the creation of instructional materials. Gachathi's team recommended that KIE produce reading and instructional materials for Kiswahili and the African languages.

Mackay's team, set up in 1981 to consider the establishment of a second university in Kenya, made drastic changes to the Kenyan education system. This is the team that introduced what has come to be known as the 8-4-4 system of education. Among other recommendations, this team made Kiswahili compulsory and examinable at all levels of the education system. Kiswahili was to be compulsory in the second university as well. The efforts made in favour of Kiswahili have begun to bear fruit. There is a very large number of Kiswahili readers for children, and the number of adult texts is increasing. A similar campaign needs to be made for each of the mother tongue languages if creative output in these languages is to prosper. 
What Ngugi, and Kenyans in general, needed was an intellectual and cultural environment which would liberate the creative force within each individual. This basic right was denied to Kenyans by the prevailing language policy. Some highly resourceful types managed to adapt and camouflage their message. For example, tucked away discreetly in Section V of Kariara and Kitonga's (1976) anthology is a collection of poetry, whose themes are little different from Ngugi's in Petals of Blood. One such poem is Jared Angira's 'Hospitality':

They left

kindly persuaded

by friendly baton

The unripe rubble of them all

came back after a kind persuasion

of the yellow sheet

The first quartile

of the celebrated score

veered persuasively

to the countryside

where peasants scratch

barren grounds

But someone left to the unknown

the referee

who once blew the whistle

And the ground where once he stood

Is mined and barbed

Is mined and barbed (63)

The use of words such as "hospitality", "kindly", and "friendly" in the heading and in the first stanza of this poem may deceive a casual reader into thinking that the message of the poem is benign. In point of fact what the poem is describing is the brutal evacuation of students from the University of Nairobi in 1969. The students had been holding a demonstration to agitate for the construction of a tunnel under Uhuru Highway to provide safer crossing between the halls of residence and the lecture halls. The key word in connection with this poem is "brutal", especially in view of the fact that the students were unarmed and the request they were making made logical sense. It takes an interest in poetry and careful reading to access Jared Angira's message. Creative works which criticise an oppressive regime such as the above poem are not always easy to find. In the case of Kenya, the majority of such gems remained unwritten in the minds of the artists.

Daring writers, like Ngugi, became openly defiant and wrote in their indigenous languages, preferring perhaps (to paraphrase the words of a famous wordsmith) to die writing than to live in silence. The majority of Kenyans played it safe by not engaging 
in creative writing. Incidentally, the underpass the students had been agitating for was eventually constructed, as quietly as the indigenous languages were allowed into the formal education system.

\section{African languages get recognition}

With the policy paper of 1999, Kenya officially recognised the indigenous languages and provided a framework for incorporating them into the formal education system (Njoroge, 2008, p. 4). This recognition came decades after Ngugi wa Thiong'o's heated campaign for Kenyans (and other Africans) to exploit to the fullest the language and cultural resources at their disposal. We would like to pay tribute to the likes of Ngugi wa Thiong'o for the spirited fight they put up, sometimes at great personal cost, in favour of indigenous Kenyan languages.

The change in policy may have come decades after their incarceration, but it is a welcome move that has already begun to bear fruit. For example, there was a time when even Kiswahili could not be used in offices. Today, Kiswahili is an official language alongside English. African languages are used as the medium of instruction in the formal education system in the first three years of primary school. In addition, there are licensed publications and radio broadcasts in various African languages: Inooro FM broadcasts in Gĩkũyũ; Mbaitũ FM broadcasts in Kĩkamba; Ramogi FM broadcasts in Dholuo.

In the 1980s, there was a bit of creative writing in the various languages of Kenya. For instance, the renowned dramatist and professor of literature at KenyattaUniversity, Francis Imbuga, has penned Lialuka lya vaana va Magomere (translated as Kagai and her brothers) among other titles. For the most part, what publishers are looking for are class readers for children in primary school classes one to three. Other than die-hards like Ngugi, Kenyan writers have produced only children's stories in mother tongue. This seems to be an indication that were the mother tongue languages to be incorporated in the formal education system at levels higher than primary class 3, Kenyan writers would rise to the occasion by producing more creative works in their local languages to meet the demand for "class readers".

In the meantime, the Text books for Social Studies have been re-written so that each province has its own text book which deals with local details of Geography, governance and cultural practices. This, we are convinced, is a step in the right direction. The next logical step would be to write those text books in the language of the majority in a given locality.

This change in policy has already had far-reaching consequences. As the intellectual and creative space was freed up and indigenous languages accorded official support and recognition in the education system (albeit only at the grassroots level), Kenyans began to write not only in their local languages, but also in the other languages available to them. Two titles, fictional works produced by Kenyans in French, come readily to mind: Chepsosir l'heroine and Le Destin aux mains. For the 1999 language policy which officially recognised the indigenous languages, perhapsthe saving grace lies in the fact that even the likes of NgugiwaThiong'o, while continuing to write in mother tongue, took to writing in English once more.His 2010 Dreams in a time of War: A childhood memoir, for example, was written in English and has no Gĩkũyũ version as yet. 


\section{Good policy, poor strategy}

In the process of "un-censoring" the creative space in Kenya, however, something seems to have gone wrong. The fact that they could now use Kiswahili and mother tongue inside the class room was taken by teachers to mean that they no longer had to use the English language correctly. Indeed, many teachers of other subjects have been heard telling students not to pay much attention to English as it is a "foreign language". This problem of attitude among teachers and students was further compounded by the "integration" policy. Where before English language and Literature in English were considered two different subjects for purposes of allocating teaching lessons on the secondary school timetable, they are currently lumped together as simply "English". This move has been lauded by teachers of other subjects because it frees up lessons on the timetable for them. In the process, it also reduces the students' contact hours with the language that continues to serve as a medium of instruction.

The net effect of these two realities, irrespective of what the policy may be on paper, is that the quality of the English language skills of the general populace is very poor. There is plenty of evidence of poor mastery of the English language: in the local newspapers, on television, inside the class room, and predictably, in the falling standards of education. There was a time when Kenyans could apply for a visa to travel to an English-speaking country without the need for a language examination. Now all such countries insist that Kenyans take the TOEFL or a similar examination.

Worse, in a country where creation of jobs should be top on the list of priorities, the current policy in the Ministry of Education renders B.Ed. (Arts) graduates whose subject combination is English and Literature unemployable. The truth of the matter is that the private sector is profit-driven. Teachers whose subject combination is English and Literature are not economically viable. Since English Language and Literature in English are now "integrated", these teachers have only one teaching subject. In their place are hired B.A. graduates who have combined either English Language or Literature in English with another subject. Since the Teachers' Service Commission (TSC) does not hire teachers without at least four years' teaching experience, a vicious cycle ensues. The result of the poor mastery of Language (any language) in Kenya is also manifest in the level of creative output (see Figure 1).

\section{The way forward}

As Kenyans rejoice in their hard-earned cultural freedom and celebrate the multi-lingual nature of Kenyan society, therefore, we plead with them and the policy makers not to do anything to adulterate the cultural and creative space, but rather to streamline it. In concluding his paper, Njoroge (2008, p.19) calls for a "workable language policy in education". We would like to suggest that the indigenous languages be accorded official language status and receive support and encouragement at all levels of the education system, but not at the expense of English. For instance, it should be made possible for students in Ukambani to take their KCPE and KCSE examination in Kikamba. The same should apply in all the other districts (or counties in the new constitutional dispensation). Alongside the structures that already existed for English, we should set up structures to teach and examine competence in the other languages used in Kenya. Such structures should include the wherewithal to produce and disseminate instructional materials. It is highly unlikely that 
Kenyans, having enjoyed the benefits of multilingualism, would stop using English or Kiswahili. But the linguistic capabilities in their first languageswould definitely improve. This would translate into improved linguistic capabilities in the second, third and subsequent languages. More importantly, the writing skills of the general populace would improve, and many more creative works would be published.

As a country, Kenya needs to urgently harness the positive energy inherent in multilingualism. The African languages must stop being just cultural artefacts and become the drivers of economic development. An organised system of teaching and testing competence needs to be established for the most vibrant languages. This will benefit native speakers of that language as well as non-native speakers who wish to learn the language.

Competing interests

The author declares that she has no competing interests.

Authors' information

Esther K. Mbithi is an ardent advocate of multilingualism. She reads literature in five languages (Kamba, Swahili, English, French and German) and is currently learning a sixth (Chinese). She is a lecturer, Literature Department, Kenyatta University, Kenya.

Received: 19 February 2014 Accepted: 15 July 2014

Published: 24 August 2014

\section{References}

Bakhtin, M. 1929. In Problems of Dostoevsky's Poetics, Translated and edited by Caryl Emerson with an introduction by Wayne Booth. Manchester, 1984, ed. E Caryl. First published in Russia in 1929.

Kariara, J. 1994. The Coming of Power. In The Winner and other Stories. Nairobi: Kenya Institute of Education.

Kariara, J, and E Kitonga. 1976. An Introduction to East African Poetry. Nairobi: Oxford University Press.

Lindfors, Bernth. 1973. Folklore in Nigerian Literature. New York: African Publishing Company.

Lodge, D. 1990. After Bakhtin: Essays on Fiction and Criticism. London and New York: Routledge.

Mbaabu, I. 1987. Facilitating the Adoption of African Languages and Educational Instruments in the African Countries: The Case of Kenya, Manuscript. Nairobi: UNESCO/KU.

Ngugiwa, T. 1981. Decolonising the Mind. London: James Currey.

Njoroge, MC. 2008. Teachers' education level and linguistic variability: Implications for Language-in-education policy in Kenya. Chemchemi 5-1: 1-26.

Ochieng, WR (ed.). 1989. A Modern History of Kenya. Ibadan: Evans Brothers.

Organisation of African Unity. 1985. BIL Publication 6. Kampala: Inter Africa Bureau of Languages.

Ricard, A. 2004. The Languages and Literatures of Africa. Cape Town: David Philip Publishers.

Sander, R, and I Munro. 1984. Tolstoy in Africa: An Interview with NgugiwaThiong'o. Critical perspectives on NgugiwaThiong'opp. 46-57. Washington: Three Continents Press.

Soyinka, W. 1988. Ethics, Ideology and The Critic, Criticism and Ideology. SIAS: Uppsala.

Williams, K. 1991. Decolonising the word: Language, culture and self in the works of NgugiwaThiong'o and Gabriel Okara. Research in African Literatures 22(4): 53-61.

doi:10.1186/s13616-014-0019-9

Cite this article as: Mbithi: Multilingualism, language policy and creative writing in Kenya. Multilingual Education 2014 4:19.

\section{Submit your manuscript to a SpringerOpen ${ }^{\circ}$ journal and benefit from:}

- Convenient online submission

- Rigorous peer review

- Immediate publication on acceptance

- Open access: articles freely available online

- High visibility within the field

- Retaining the copyright to your article 